Article

\title{
Experimental Study on the Sustainability Assessment of AWJ Machining of Ti-6Al-4V Using Glass Beads Abrasive Particles
}

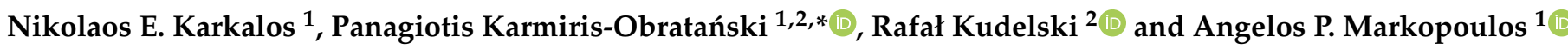 \\ 1 Laboratory of Manufacturing Technology, School of Mechanical Engineering, National Technical University \\ of Athens, 15780 Athens, Greece; nkark@mail.ntua.gr (N.E.K.); amark@mail.ntua.gr (A.P.M.) \\ 2 Department of Manufacturing Systems, Faculty of Mechanical Engineering and Robotics, AGH University of \\ Science and Technology, 30-059 Cracow, Poland; kudelski@agh.edu.pl \\ * Correspondence: karmiris@agh.edu.pl
}

check for

updates

Citation: E. Karkalos, N.;

Karmiris-Obratański, P.; Kudelski, R.;

Markopoulos, A.P. Experimental

Study on the Sustainability

Assessment of AWJ Machining of

Ti-6Al-4V Using Glass Beads

Abrasive Particles. Sustainability 2021

13, 8917. https://doi.org/10.3390/

su13168917

Academic Editor: Ashutosh Tiwari

Received: 6 July 2021

Accepted: 6 August 2021

Published: 9 August 2021

Publisher's Note: MDPI stays neutral with regard to jurisdictional claims in published maps and institutional affiliations.

Copyright: (c) 2021 by the authors. Licensee MDPI, Basel, Switzerland. This article is an open access article distributed under the terms and conditions of the Creative Commons Attribution (CC BY) license (https:// creativecommons.org/licenses/by/ $4.0 /)$.

\begin{abstract}
Abrasive Waterjet Machining (AWJM) is considered a viable alternative to conventional machining processes, due to its capability of rendering even complex features on parts with high productivity. However, it is currently also important for manufacturing processes to comply with the various aspects of sustainability, by putting emphasis on the environmental dimension apart from the economic. Although AWJM generally is considered an inherently environmentally friendly process, it is required that thorough experimental studies be carried out to evaluate the sustainability of AWJM under various conditions. In the present work, AWJM experiments under various conditions were conducted on a Ti-6Al-4V workpiece in order to determine the optimal conditions leading to a high degree of sustainability in this process based on several indicators. The experiments were carried out using glass beads, which act as an eco-friendly abrasive. After the basic outcome of the experiment was analyzed to determine the correlations between process parameters and depth of penetration, kerf width, and kerf taper angle, sustainability analysis with the aid of Grey Relational Analysis (GRA) was conducted. The optimum solution provided a sufficiently high score regarding both the economic and environmental dimensions of sustainability.
\end{abstract}

Keywords: AWJM; slot machining; glass beads; Ti-6Al-4V; sustainability evaluation; GRA

\section{Introduction}

The manufacturing sector plays a considerable role regarding the financial status of various industrialized countries, both developed and developing. It is estimated that, in the USA, $31 \%$ of energy consumption is related to manufacturing industries, and $19 \%$ of the total greenhouse gas emissions in the EU are related to the manufacturing sector [1]. Moreover, as per the World Bank data for 2018-2019, 15.4\% of the world GDP is related to the manufacturing sector, with the percentage varying between $9-14 \%$ for the USA, UK, Russia, and India, whereas in China manufacturing plays a more considerable role, as $27 \%$ of the country's GDP is related to the added value from manufacturing [2]. In the 21st century, a challenge for industry is to both manufacture components with the best quality at the lowest possible cost and achieve a clean and sustainable production. This ecological aspect is related to efficient waste management [3] combined with lowering energy and time consumption, recycling, and generally minimizing the environmental impact of manufacturing processes [4].

As it is generally more difficult for conventional machining processes to comply with the basic goals of sustainability to a high degree, even with the current trends that include eco-friendly concepts such as Mininum Quantity Lubrication (MQL) and the use of biodegradable cooling fluids, alternative processes need to be evaluated in order to replace the conventional ones, not only with a view to achieve high levels of productivity at affordable costs, but to achieve other goals of sustainable production as well. Abrasive Waterjet (AWJ) cutting is an environmentally friendly non-conventional machining process 
that involves a high-pressure beam of water combined with abrasive particles that cut any material without increasing the material's temperature considerably [5]. As a result, the processed material is not subject to thermal deformation and changes in properties caused by increased temperature. Moreover, no hazardous gases are produced by AWJ cutting, and no chemical contamination occurs, as there is no need for any cutting fluid. Nevertheless, as sustainability is a complex, multi-dimensional concept, this process can become even more environmentally benign from other points of view as well, when the most appropriate process conditions are selected.

One of the most important applications of AWJ technology is AWJ milling. An efficient stream of liquid, with an increased pressure at a value of about $1300-4000$ bar, is usually employed on a CNC machine, which allows the rendering of a large variety of shapes, while also guaranteeing precision and the repeatability of dimensions [6]. This method of material processing ensures low production costs, translating into a lower price for the finished element. Although AWJ is mostly used for cutting through material, usually it is also being employed for Control Depth Cutting (CDC). This can be achieved by controlling the process parameters, namely the traverse speed $\left(\mathrm{v}_{\mathrm{t}}\right)$, the stand-off distance $(\mathrm{h})$, the abrasive flow rate $\left(m_{a}\right)$, and the jet pressure (p) [7-9]. The erosion process that eventually leads to the desired material removal during AWJM occurs due to the pressure of the water and the impact of the abrasive. AWJM is a time-dependent process, since the traverse feed rate is an essential parameter for controlling the Material Removal Rate (MRR). As the jet moves faster, fewer particles will strike the material, and the MRR will be lower [10-12].

Due to the importance of proper regulation of process parameters, various relevant studies have been conducted. Alberdi et al. [13] predicted the kerf geometry by analyzing the process parameters during AWJM of an AA 7075-T651. They found that the most important parameter that affects the kerf width is the stand-off distance. Rabani et al. [10] used partial non-linear differential equations to control the AWJM parameters and predict the slots while machining a Ti6Al4V titanium alloy. The results show that errors were reduced, and the accuracy was improved by $50 \%$. Using this algorithmic methodology, the experimental set-up time could be reduced by at least $200 \%$. AWJ milling of near-netshape fabrication of TNM-B1 titanium aluminide was investigated by Uhlmann, Männel, and Braun [14]. The research study was focused on increasing the producible geometries by controlling the kerf width and kerf depth to increase the efficiency of control depth cutting operations. Yuan et al. [12] used AWJ milling techniques to produce circular pockets in a titanium grade 5 alloy. Based on a Box-Behnken statistical design, the authors tried to determine the machining parameters' proper combination (i.e., $\mathrm{h}, \mathrm{m}_{\mathrm{a}}, \mathrm{v}_{\mathrm{t}}$, and $\mathrm{p}$ ). Experimental results were successfully validated by a prediction model with a maximal deviation of 3.5\% in the average milling depth. Finally, Chithirai Pon Selvan et al. [15] used the Regression Investigation Method and Artificial Neural Network method to find the process parameters' performance analysis. The empirical model showed that the pressure and the abrasive mass flow rate are proportional to the depth of penetration of a Ti6Al4V workpiece.

Apart from the process parameters, the characteristics of the abrasive particles play an important role in the outcome of AWJM. Due to the nature of the erosion process, many experiments have found that particles with lower velocities tend to embed grit into the workpiece material $[16,17]$. On the other hand, researchers have reported that the embedded particles are fragments of the abrasive grit [18-21]. The study of Stachowiak and Stachowiak [22] revealed that the abrasive shape, rather than the abrasive hardness, plays a key role in the grit embedment. They observed that the particles' angular shape generates up to four times higher particle embedment compared to the spherical shape of the glass beads. Researchers Fowler, Shipway, and Pashby $[18,23,24]$ investigated the AWJM of titanium grade 5 as well as the effects of particle hardness and grit embedment during this operation. It was shown that MRR is strongly correlated with particle hardness and size. Additionally, the traverse speed is an essential parameter of the process. By increasing the $v_{t}$ and the MRR, the surface waviness and the particle embedment are 
decreased. Perec [11] used three different abrasives (i.e., crushed glass, garnet, and olivine) to investigate the AWJ milling of titanium Ti6Al4V workpiece. The research investigation involved the cutting depth performance of each abrasive and the wear of the focusing tube. The experimental results revealed that the highest cutting depth could be achieved using garnet as abrasive right after olivine. On the other hand, the olivine abrasive caused the most increased wear of the focusing tube. An experimental case study performed by Yu et al. [25] took into consideration the above-mentioned machining parameters and the abrasive materials (garnet, alumina, and silicon carbide) and their mixtures. It was found that the mixture of $75 \%$ of alumina and $25 \%$ of garnet leads to deep cuttings with very low surface roughness during AWJ machining of an aluminum alloy block.

Although a considerable amount of work has been conducted on sustainability assessment of conventional machining processes, the works related to sustainability studies of AWJ cutting are much fewer and can be categorized into three main groups, namely works related to the use of recycled or eco-friendlier abrasives, sustainable variants of AWJ cutting, or cutting of eco-friendly materials. Boud et al. [26] proposed the use of softer, soluble abrasives for AWJ machining. In their work, they compared the use of garnet abrasive with two types of soluble abrasives: MaxxStrip, which is based on kieserite mineral, and SoftStrip, based mainly on sodium bicarbonate. Based on experiments conducted on four different materials, it was found that although lower Material Removal Rates were achieved by soluble abrasives, their efficiency was considerably higher than that of plain waterjet. Moreover, although the contamination area was smaller, grit embedment was still extant in the case of soluble abrasives, and cleaning of the workpieces occurred after post-machining treatment. Kantha Babu and Krishnaiah Chetty [27] studied the effect of using recharged abrasives during AWJM with a view to achieve the best compromise between cutting efficiency and cost. The recharged abrasives were anticipated to perform better than simple reused abrasives, as they contained a percentage of fresh abrasives. Their findings indicated that a considerable increase in depth of cut occurs with a $40 \%$ recharging and that surface roughness was minimized with a $60 \%$ recharging, and an increase in recharging percentage also resulted in a small increase in kerf width and taper. Sabarinathan, Annamalai, and Rajkumar [28] investigated the use of grinding-wheel waste as an alternative abrasive for AWJM. After the abrasives were examined by using SEM and EDX analysis, their performance was compared to that of garnet regarding MRR, depth of penetration, and kerf dimension. MRR of recycled alumina was found to be higher in any case, but it also resulted in higher kerf width and surface roughness; thus, it is better suited for rough machining. Perec [11] conducted a thorough comparison between two common abrasives, namely garnet and corundum, regarding their recycling potential. Corundum showed higher recycling rate in some cases, but focusing tube wear was almost 60 times greater. Kandasamy, Vimal and Senthuram [29] conducted a study on the determination of traces of metals in the waste water from AWJM process and calculated the embodied product energy of the process.

Regarding more sustainable variants of AWJM, Natarajan et al. [30] proposed cryogenicassisted AWJM. In their work, they conducted experiments at three levels of pressure, abrasive mesh size, and jet impact angle with and without the use of liquid nitrogen. Regarding depth of penetration, in every case, the application of liquid nitrogen enabled greater depths of penetration, lower taper ratio, higher MRR, lower surface roughness, lower contamination, different microstructure, and higher microhardness. Pradhan, Das, and Dhupal [31] evaluated the efficiency and sustainability of hot AJM, a new variant of AJM using compressed air instead of waterjet and hot abrasives. In their work, experiments were carried out under various air pressure, stand-off distance, and abrasive temperature values. It was found that the temperature of the abrasives most affected the surface roughness, whereas the air pressure most affected the kerf taper and MRR. The hot AJM process led to lower energy consumption but higher cost. Finally, a novel sustainable alternative of WJM, namely Ice Jet Machining and its variants, was presented and evaluated by Gupta et al. [32]. 
Based on the literature review, it can be seen that there is a lack of comprehensive work on sustainability assessment of AWJ machining based on several indicators. Thus, in this experimental study, a sustainability assessment of AWJM of Ti-6Al-4V under various process conditions was carried out, taking into consideration indicators from both economic and environmental dimensions of sustainability. For the experiments, an environmentally friendly abrasive, namely glass beads, was used. After the experimental results are analyzed, the sustainability of each experimental case is evaluated by means of GRA in order to determine the optimum conditions.

\section{Sustainability Assessment in Manufacturing}

According to Jayal et al. [33], various manufacturing concepts related to sustainability or at least some of its elements evolved as distinct concepts around 2010 and exhibit different levels of potential. These concepts are lean manufacturing, which is mainly based on waste reduction; green manufacturing, which is based on the 3R concept; and finally, sustainable manufacturing, which is the most innovative concept, based on the 6R concept. The 3R concept, namely "reduce, reuse, recycle," and the 6R concept, namely "reduce, reuse, recover, redesign, remanufacture, recycle," are two of the most frequently used concepts in order to establish a more green approach in manufacturing [34]. It is important to note that sustainability is related not only to the manufacturing stage, but to all the product life-cycle stages such as pre-manufacturing, use, and post-use as well $[33,35,36]$.

An important categorization of sustainability dimensions is the well-known concept of the "three pillars", namely the economic, social, and environmental dimensions. These three dimensions are related to the aspects of economy, ecology, equity, work, and knowledge [37]. More specifically, the first pillar is related to industry, the second is related to the human capital society, and the third one to nature [37]. A relevant sustainability framework is termed as the "Triple Bottom Line" (TBL or 3E) and aims at the amelioration of the state of the three pillars, which will subsequently ameliorate the condition of the technological and natural ecosystems. Each dimension has a specific function [37]; for example, the role of the economic dimension is to relate the sustainability of machining processes with financial strategies and ensure that these processes are feasible from a techno-economic point of view. The environmental dimension is related to the reduction of the negative environmental impact caused by machining processes, e.g., by decreasing energy and resource consumption. Furthermore, the social dimension includes efforts towards achieving safer workplaces, elimination of health threats, and improvement of productivity.

In some cases, the concept of the three dimensions can be expanded with additional categories and their respective indicators. For example, Jamil et al. [38], in an assessment of the sustainability of welding processes, included the final properties of the weld as an additional category, termed physical performance, and Bork et al. [39] related the economic pillar to a technological one in a unified "economic-technological" pillar.

In the relevant literature on conventional machining processes, another commonly accepted categorization of sustainability aspects is that of Jawahir et al. [40], who selected the six most significant parameters regarding sustainability of manufacturing processes: waste management, manufacturing cost, environmental impact, energy consumption, personnel health, and operational safety. These six parameters or elements are interacting, and their contributions constitute the total process sustainability index [33,41]. Waste management is relevant to recycling and disposal of wastes produced during the manufacturing processes, and it is necessary to develop means to reduce waste and its subsequent emissions and treat it properly before disposal, especially that which is toxic or otherwise harmful [35,40]. Manufacturing cost is relevant to the costs of the equipment required for the manufacturing process and the costs during the process [40]. However, indirect costs related to environmental or social factors can be also incorporated into the total cost [35]. The environmental impact is related to factors which lead to environmental pollution such as toxic materials, metallic dust, and emissions. Energy consumption can be estimated by monitoring the power consumption during manufacturing processes and can 
be minimized by various means. Finally, personnel health and operational safety are two important aspects that are not so frequently taken into consideration in relevant studies. Workers should not be exposed to harmful mist and vapors or various chemical substances, and their workplace should be properly designed in order to ensure safety during various manufacturing processes.

Apart from the general concepts related to sustainability, it is necessary to define more specific quantities or indicators in order to evaluate the sustainability of various systems. According to Singh et al. [42], sustainability indicators are appropriate criteria aiming to quantify the different states and dimensions of the concept of sustainability and can be divided into two different categories, namely quantitative and qualitative indicators, or according an alternative definition by Bork [39], objective and subjective metrics. Examples of quantitative indicators or objective metrics are power consumption and carbon dioxide emissions, which can be directly measured, whereas qualitative indicators or subjective metrics are those which cannot be directly quantified, such as personnel safety and health risk [1]. These indicators can also be quantified by appropriate scoring systems, which are used by experts in the respective field in order to assign a numerical value to each different state of a qualitative indicator. Suitable criteria should meet several requirements [1] and can be categorized in different dimensions such as the aforementioned 3E.

Najiha, Rahman, and Kadirgama [43] argued that there is a non-deterministic component of sustainability that also needs to be taken into consideration by fuzzy logic models. In fact, half of the aforementioned elements of sustainability, namely manufacturing cost, power consumption, and waste management, can be considered as deterministic and can be calculated by analytical formulas, whereas the other three can be considered as non-deterministic and thus can be described by fuzzy variables $[33,41]$.

In order to calculate the total sustainability index for a specific process, the sustainability dimensions and their indicators should be properly organized into various hierarchical levels. In the relevant literature, various alternative procedures exist regarding the number and theme of the hierarchical levels. The first level usually includes general sustainability aspects, followed by their subcategories in the second level, and more specific indicators in the final levels. In the work of Najiha, Rahman, and Kadirgama [43], three hierarchical levels of sustainability factors used for the calculation of the sustainability index were defined, with the first one including aspects such as environmental friendliness, the second one including factors such as level of recycling, and the third one including more specific factors such as the chip recycling rate. A hierarchical structure of three levels was also proposed by Bork et al. [39] and Kim, Leong, and Chen [44], including a level of individual metrics, a level of sub-indices, and the level of sustainability index. The sub-index level is related to individual aspects of sustainability based on the 3E. Badurdeen et al. [36] included five different levels from the index to the individual metric level, such as the sub-index, cluster and sub-cluster levels. In the sub-index level, the three pillars of sustainability can be considered, and then they are further analyzed in the next levels. For example, the economy can be analyzed as initial investment, costs, benefits, and losses; initial investment can be analyzed as capital, R\&D, and employee training cost; and finally, capital cost is calculated based on equipment and facility costs.

An alternative categorization of sustainability aspects into different levels is relevant to the different areas of importance or different stages of production. Various researchers have included different numbers of hierarchical levels. For example, Jayal et al. [33] included three different levels, namely product, process, and system. In each level, different methodologies can apply, and the weighting of similar indicators may be different as affects this level to a higher or lesser degree. Moreover, the sustainability index (SI) can be defined in different levels [36], e.g., the ProdSI in the product level or the ProcSI in the process level. Especially in the product level, the 3R and 6R concepts are considered important. Feng, Joung, and Li [45] proposed a much broader analysis including seven different levels, namely global, country, sector, corporation, facility, process, and product, whereas Kim, Leong, and Chen [44] used five of them, excluding sector and facility. In a 
machining workshop [46], the sustainability assessment process can include layers such as machine tool, manufacturing unit, manufacturing task, and workshop layer. Although a hierarchy exists between the four layers, each layer interacts with the others, and finally the energy consumption state is determined through effective energy and specific energy consumption indicators.

After the levels and the metrics in each level are selected, the sustainability assessment can be carried out. Usually, the whole procedure includes the following five steps, depicted also in Figure 1:

(1) Categories and indicators of sustainability are defined. Indicators which are not useful or do not have a noticeable effect for the specific system are not included.

(2) The values of all indicators are properly normalized in order to eliminate any artificially created relatively higher influence of some indicators due to their absolute values.

(3) The indicators of each category are assigned weights according to their importance towards the final goal.

(4) An aggregation procedure is carried out, using scores and weights of each category to calculate an overall sustainability score.

(5) Finally, the sustainability scores of all assessed processes are compared.

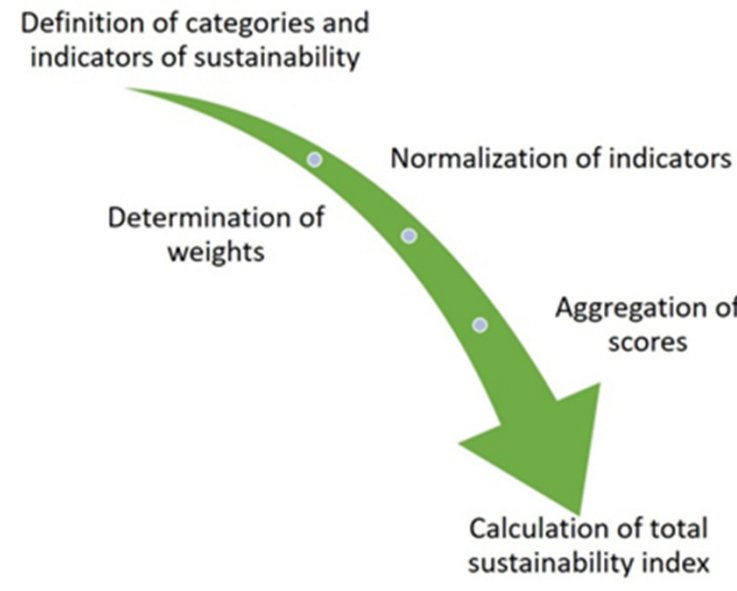

Figure 1. Sustainability assessment steps.

In order to carry out the evaluation process or critical parts of it such as the determination of weights and aggregation of scores, various established methodologies can be used. In the relevant literature, sustainability-specific methods such as LCA (Life Cycle Assessment); general application methodologies such as TOPSIS [47], AHP [48], fuzzy AHP [49], and GRA [50]; and optimization approaches such as desirability approach or genetic algorithms [34] are used.

\section{Materials and Methods}

The present study contains AWJ slot-milling experiments under different process conditions, using glass beads as abrasive, in order firstly to determine the effect of process parameters such as jet pressure (denoted as $\mathrm{p}$ ), abrasive mass flow rate (denoted as $\mathrm{m}_{\mathrm{a}}$ ), and traverse speed (denoted as $\mathrm{v}_{\mathrm{t}}$ ) on kerf characteristics under constant stand-off distance of $3 \mathrm{~mm}$, and then to evaluate the sustainability of AWJ milling process under various conditions, presented in Table 1 and depicted in Figure 2, using multiple criteria. 
Table 1. Machining parameters.

\begin{tabular}{cc}
\hline Machining Parameters & Levels \\
\hline Pressure $(\mathrm{MPa})$ & 150,300 \\
Traverse speed $(\mathrm{mm} / \mathrm{min})$ & $200,400,600$ \\
Abrasive mass flow rate $(\mathrm{g} / \mathrm{s})$ & $0.5,1,2,5,8$ \\
Stand-off distance $(\mathrm{mm})$ & 3 \\
Type of abrasive & glass beads \\
\hline
\end{tabular}

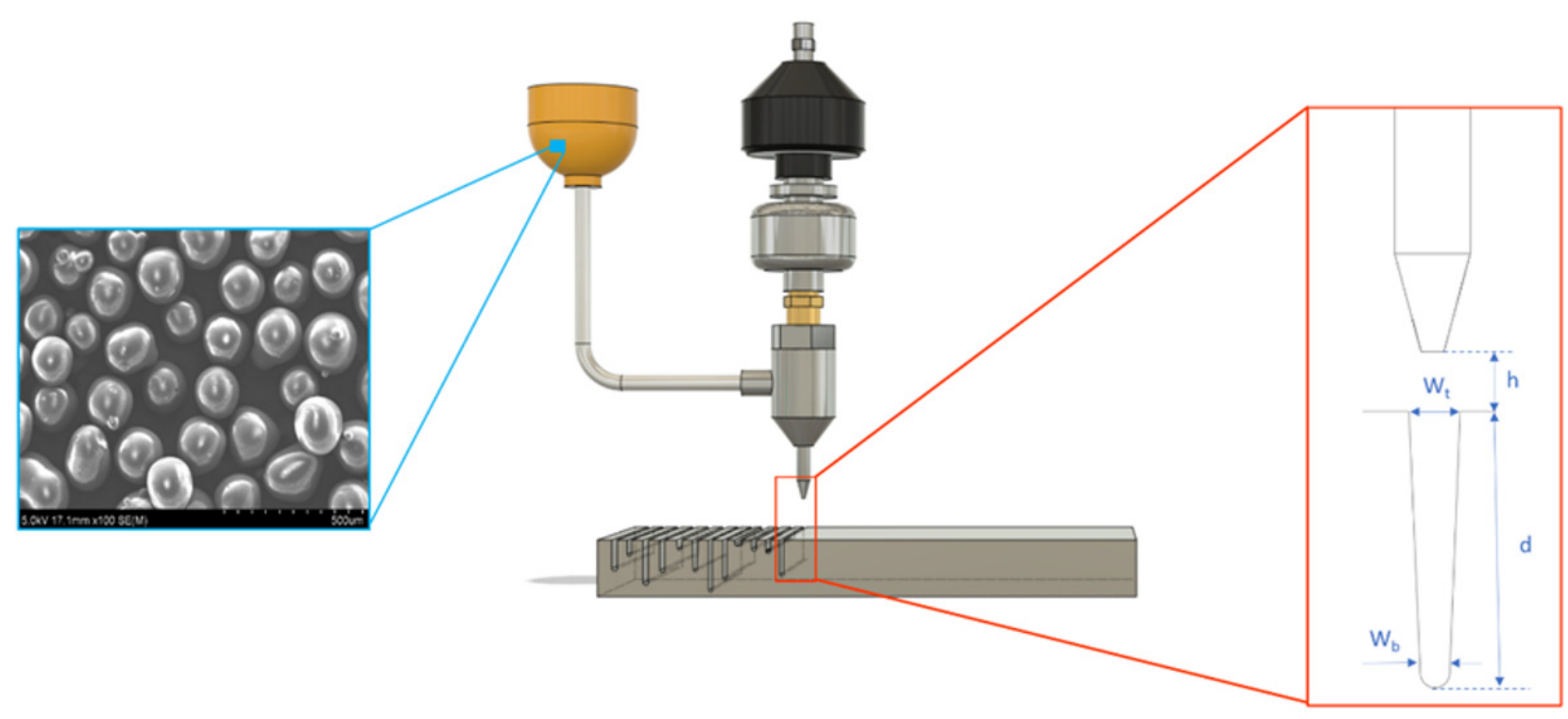

Figure 2. Schematic representation of the AWJ milling experimental setup with a SEM image of the abrasive and the basic geometrical characteristics of the slot.

Straight slots with a length of $50 \mathrm{~mm}$ were created in a Ti-6Al-4V box-shaped workpiece with dimensions of $200 \times 50 \times 24 \mathrm{~mm}$. The chemical composition of the workpiece material is shown in Table 2, whereas its hardness value was HV430. The experiments were carried out in a H.G. RIDDER Automatisierungs-GmbH model HWE-P1520 machine. The focusing tube had a diameter of $1 \mathrm{~mm}$, and the waterjet nozzle had a diameter of $0.3 \mathrm{~mm}$, whereas the jet impingement angle was $90^{\circ}$. The abrasive particles used were glass beads, depicted in the SEM micrograph of Figure 3, which had a mesh size of 80, were composed mainly of $\mathrm{SiO}_{2}$ (as can be seen in Table 3), had a density of $2500 \mathrm{~kg} / \mathrm{m}^{3}$, and had a hardness on the Mohs scale of 6 , as per the supplier's specifications (TEPARK, Brzeg, Poland). Using the glass beads, a total of 30 experimental runs were carried out, using a full factorial design with three parameters each at different levels, namely 3 for the traverse speed, 5 for the abrasive mass flow rate, and 2 for jet pressure. The range of these parameter level values is sufficiently wide in order to also observe sufficiently variable responses within the range allowed by the equipment restrictions. It is worth mentioning that before the actual experimental procedure, a series of recurrent tests took place under different conditions in order to ensure the repeatability of the slot dimensions obtained in each case.

Table 2. Chemical composition of Ti6Al4V (\%).

\begin{tabular}{cccccccc}
\hline Ti & Al & V & C & O & N & H & Fe \\
\hline 90 & 6 & 4 & 0.1 & 0.2 & 0.05 & 0.0125 & 0.3 \\
\hline
\end{tabular}




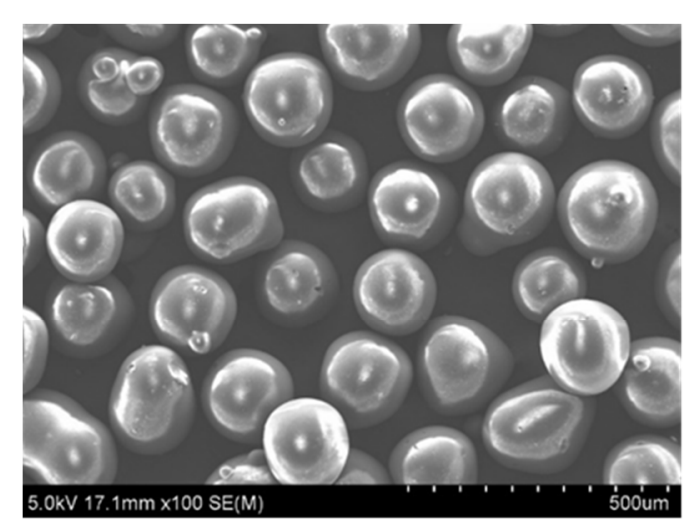

(a)

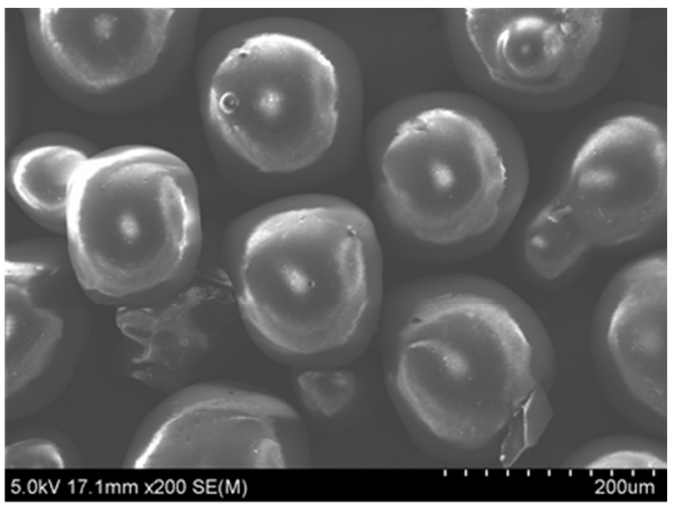

(b)

Figure 3. SEM micrographs of the abrasive material used for the study with a magnification of: (a) $100 \times$, (b) $200 \times$.

Table 3. Chemical composition of the glass beads (w\%).

\begin{tabular}{ccccccc}
\hline $\mathrm{SiO}_{2}$ & $\mathrm{Na}_{\mathbf{2}} \mathbf{O}$ & $\mathrm{CaO}$ & $\mathbf{M g O}$ & $\mathrm{Al}_{\mathbf{2}} \mathrm{O}_{\mathbf{3}}$ & $\mathrm{Fe}_{\mathbf{2}} \mathrm{O}_{3}$ & $\mathrm{TiO}_{\mathbf{2}}$ \\
\hline $70-73$ & $13-15$ & $7-11$ & $3-5$ & $0.5-2$ & 0.1 & 0.1 \\
\hline
\end{tabular}

The abrasive particles employed in the experiments, namely micro-glass beads, have diameters between 100 and $200 \mu \mathrm{m}$. Glass beads (microspheres) constitute an extremely resistant non-metallic abrasive with a smooth surface. Using this product for cleaning gives excellent results consistently. It is a chemically inert material. Therefore, its impact on the erosive abrasion of the treated surface is minimal. Moreover, it is an environmentally friendly abrasive, and it can be reused, as it is free of crystalline silica. Although AWJ machining with garnet abrasive is more usual due to the relatively lower price and higher Material Removal Rates obtained with this abrasive, using glass beads can be advantageous due to their higher potential for recyclability. This glass-type abrasive has proven essential in the aerospace industry, because other abrasives damage surfaces. Due to their spherical shape, they produce a smoother surface that delays crack and corrosion formation.

A digital ultra-deep-field VHX-7000 Focus Variation Microscope (FVM) was used to measure the slots' geometrical characteristics. The microscope is equipped with two lenses capable of a range magnification between 20 and $2000 \times$. The focus variation method is based on a white LED light source that passes through a transparent mirror and is followed by a lens until it reaches the surface. This technique is very similar to confocal microscopy. The reflected light follows back along the same above-mentioned route until it reaches the sensor's charging device. Depending on the sample's vertical position relative to the lens, the sensor detects the focused points. These focused points on each image create a fully focused image composed of multiple images. This technique enables a three-dimensional surface representation. The following Figure 4 shows aVHX-7000 digital microscope (Keyence, Mechelen, Belgium) and a typical AWJ slot. For the SEM micrographs, a HITACHI SU-70 analytical field-emission SEM was used. 


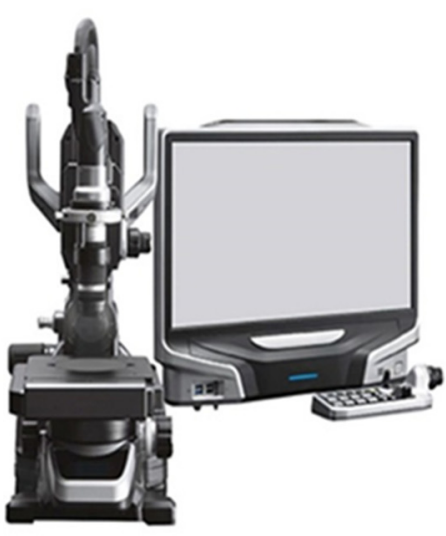

(a)

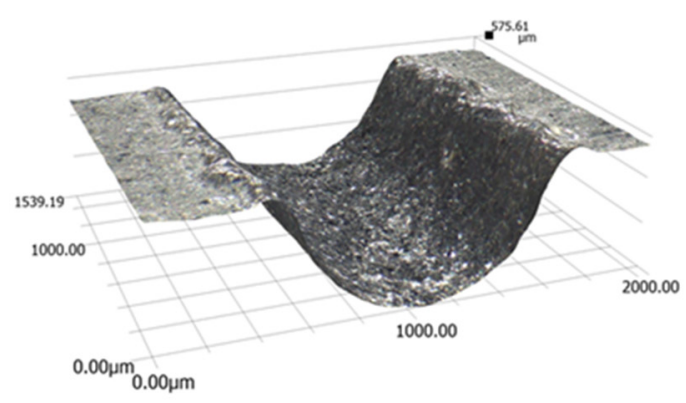

(b)

Figure 4. Images of: (a) the microscope used in the measurement process, (b) an indicative slot.

\section{Results and Discussion}

\subsection{Analysis of Experimental Results}

After the experiments were carried out, results regarding depth of penetration (d) and kerf width (w) were obtained, and kerf taper angle (a) was calculated as follows:

$$
\mathrm{a}=\tan ^{-1}\left(\frac{\mathrm{W}_{\mathrm{t}}-\mathrm{W}_{\mathrm{b}}}{2 \mathrm{~d}}\right)
$$

These results are summarized in Table 4. It can be seen that the values of depth of penetration vary considerably from 0.377 to $8.114 \mathrm{~mm}$, whereas the standard deviation varied between 0.001 and $0.044 \mathrm{~mm}$. Regarding top kerf width, the values varied between 1.094 and 1.375, with standard deviation between 0.007 and $0.059 \mathrm{~mm}$, and finally, kerf taper angle values varied between 0.887 and 20.685 degrees, with standard deviation between 0.116 and 2.560 degrees. Some of the produced grooves can be seen in Figure 5.

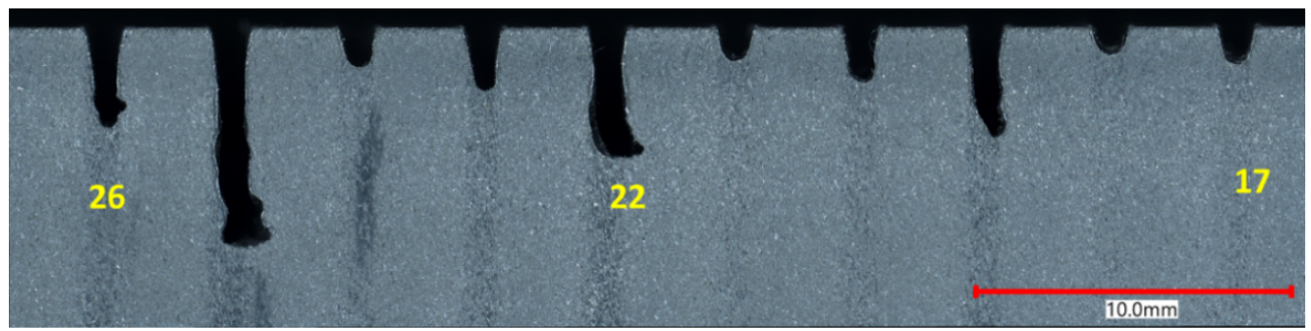

Figure 5. Shows the form, right to left, of the grooves from the 17th to the 26th.

As was anticipated, depth of penetration increases with lower traverse speed due to shorter time of interaction between the abrasive jet and the workpiece. Although the depth of penetration values were considerably lower than in cases where harder abrasives such as garnet are used, the material removal with glass beads was relatively effective. From the experimental findings depicted in Figure 6, it can be seen that the correlation of depth of penetration with traverse feed was not linear for either jet pressure value, as the depth of penetration decreased considerably when the traverse speed increased from 200 to $400 \mathrm{~mm} / \mathrm{min}$, whereas a much smaller decrease was observed for traverse speed values between 400 and $600 \mathrm{~mm} / \mathrm{min}$. A nonlinear correlation is also found to exist between depth of penetration and abrasive mass flow rate, as the rate of increase of depth of penetration in respect to the increase in abrasive flow rate is decreasing, and finally, for higher traverse speeds it reached an almost-constant value, indicating that material removal efficiency reaches a limit value. Finally, the impact of jet pressure is also high, as the twofold increase in jet pressure led to 3-7 times greater depths, and the kinetic energy of 
the jet was considerably higher. These observations are supported by the ANOVA results, which indicate that jet pressure is the most important parameter with a relative significance of $55.47 \%$, followed by traverse speed $(28.57 \%)$ and abrasive mass flow rate $(16.06 \%)$. Thus, appropriate regulation of depth of penetration can be primarily achieved by jet pressure.

Table 4. Experimental results.

\begin{tabular}{|c|c|c|c|c|c|c|c|c|c|}
\hline No. & $\begin{array}{c}\mathrm{v}_{\mathrm{t}} \\
(\mathrm{mm} / \mathrm{min})\end{array}$ & $\begin{array}{c}\mathrm{m}_{\mathrm{a}} \\
(\mathrm{g} / \mathrm{s})\end{array}$ & $\begin{array}{c}\mathrm{p} \\
(\mathrm{MPa})\end{array}$ & $\begin{array}{c}\mathrm{d} \\
(\mathrm{mm})\end{array}$ & $\begin{array}{c}\sigma_{d} \\
(\mathrm{~mm})\end{array}$ & $\begin{array}{c}W \\
(\mathrm{~mm})\end{array}$ & $\begin{array}{c}\sigma_{w} \\
(\mathrm{~mm})\end{array}$ & $\begin{array}{c}a \\
(\mathrm{deg})\end{array}$ & $\begin{array}{c}\sigma_{\mathrm{a}} \\
(\mathrm{deg})\end{array}$ \\
\hline 1 & 200 & 0.5 & 150 & 0.693 & 0.012 & 1.192 & 0.025 & 10.518 & 1.049 \\
\hline 2 & 400 & 0.5 & 150 & 0.509 & 0.005 & 1.146 & 0.007 & 15.027 & 0.422 \\
\hline 3 & 600 & 0.5 & 150 & 0.377 & 0.003 & 1.102 & 0.023 & 14.089 & 1.751 \\
\hline 4 & 200 & 1.0 & 150 & 0.801 & 0.002 & 1.170 & 0.011 & 8.358 & 0.394 \\
\hline 5 & 400 & 1.0 & 150 & 0.573 & 0.003 & 1.181 & 0.031 & 10.282 & 1.549 \\
\hline 6 & 600 & 1.0 & 150 & 0.436 & 0.001 & 1.125 & 0.039 & 20.685 & 2.560 \\
\hline 7 & 200 & 2.0 & 150 & 0.831 & 0.003 & 1.158 & 0.034 & 7.458 & 1.172 \\
\hline 8 & 400 & 2.0 & 150 & 0.604 & 0.001 & 1.152 & 0.028 & 10.098 & 1.329 \\
\hline 9 & 600 & 2.0 & 150 & 0.539 & 0.001 & 1.135 & 0.025 & 9.738 & 1.329 \\
\hline 10 & 200 & 4.0 & 150 & 0.999 & 0.005 & 1.236 & 0.034 & 7.997 & 0.976 \\
\hline 11 & 400 & 4.0 & 150 & 0.657 & 0.003 & 1.175 & 0.010 & 9.598 & 0.438 \\
\hline 12 & 600 & 4.0 & 150 & 0.588 & 0.002 & 1.295 & 0.025 & 15.951 & 1.219 \\
\hline 13 & 200 & 8.0 & 150 & 1.112 & 0.003 & 1.345 & 0.027 & 10.142 & 0.696 \\
\hline 14 & 400 & 8.0 & 150 & 0.683 & 0.004 & 1.259 & 0.015 & 10.663 & 0.632 \\
\hline 15 & 600 & 8.0 & 150 & 0.572 & 0.001 & 1.254 & 0.023 & 14.208 & 1.151 \\
\hline 16 & 200 & 0.5 & 300 & 2.605 & 0.005 & 1.286 & 0.025 & 4.8603 & 0.275 \\
\hline 17 & 400 & 0.5 & 300 & 1.212 & 0.009 & 1.263 & 0.018 & 6.889 & 0.429 \\
\hline 18 & 600 & 0.5 & 300 & 0.925 & 0.006 & 1.253 & 0.010 & 7.816 & 0.314 \\
\hline 19 & 200 & 1.0 & 300 & 3.519 & 0.005 & 1.334 & 0.053 & 3.083 & 0.431 \\
\hline 20 & 400 & 1.0 & 300 & 1.785 & 0.003 & 1.270 & 0.028 & 6.320 & 0.450 \\
\hline 21 & 600 & 1.0 & 300 & 1.103 & 0.002 & 1.256 & 0.011 & 7.800 & 0.286 \\
\hline 22 & 200 & 2.0 & 300 & 4.112 & 0.020 & 1.327 & 0.039 & 2.214 & 0.272 \\
\hline 23 & 400 & 2.0 & 300 & 2.027 & 0.003 & 1.200 & 0.022 & 4.907 & 0.311 \\
\hline 24 & 600 & 2.0 & 300 & 1.294 & 0.001 & 1.222 & 0.018 & 7.033 & 0.399 \\
\hline 25 & 200 & 4.0 & 300 & 7.014 & 0.044 & 1.272 & 0.031 & 0.887 & 0.127 \\
\hline 26 & 400 & 4.0 & 300 & 3.212 & 0.004 & 1.275 & 0.013 & 4.319 & 0.116 \\
\hline 27 & 600 & 4.0 & 300 & 1.773 & 0.004 & 1.266 & 0.029 & 4.947 & 0.469 \\
\hline 28 & 200 & 8.0 & 300 & 8.185 & 0.009 & 1.375 & 0.059 & 1.526 & 0.207 \\
\hline 29 & 400 & 8.0 & 300 & 3.901 & 0.008 & 1.335 & 0.021 & 4.247 & 0.154 \\
\hline 30 & 600 & 8.0 & 300 & 1.982 & 0.004 & 1.261 & 0.025 & 4.525 & 0.362 \\
\hline
\end{tabular}

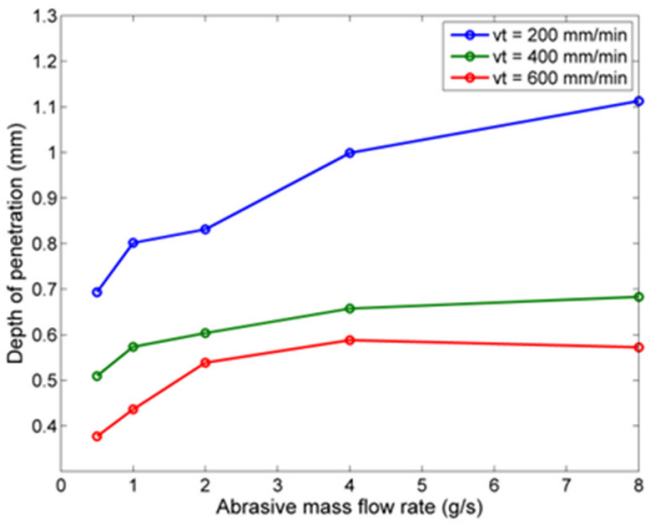

(a)

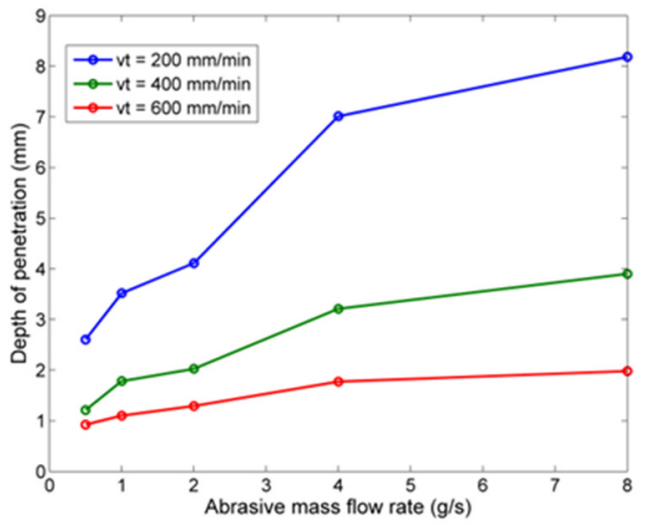

(b)

Figure 6. Depth of penetration variation in respect to abrasive mass flow rate and traverse speed for jet pressure values of: (a) $150 \mathrm{MPa}$, (b) $300 \mathrm{MPa}$. 
In the case of top kerf width, it was found that higher traverse feed led to lower top kerf width, and higher jet pressure led to an increase in kerf width, as can be seen in Figure 7. These trends are justified, as for a fixed stand-off distance, the greater speed leads to shorter impact time between the jet and the workpiece, and subsequently to narrower slots, but higher jet pressure leads to more intense impact, and thus more material is removed from areas around the slot. For the abrasive mass flow rate, the trend was not monotonic, as between $0.5-2.0 \mathrm{~g} / \mathrm{s}$, a slight increase followed by a slight decrease in kerf width was observed, and then the anticipated clear increase in kerf width for higher abrasive mass flow rate values was obtained. This trend implies that although higher $\mathrm{m}_{\mathrm{a}}$ leads to increased material removal, a certain limit should be imposed in order to avoid excessive top kerf width values. ANOVA analysis showed that jet pressure was the most significant factor with relative significance of $50.14 \%$, followed by abrasive mass flow rate $(36.96 \%)$ and traverse speed $(12.90 \%)$. These results imply that at a constant stand-off distance value, the kerf width can be effectively regulated by adjusting jet pressure in order to obtain narrower slots.

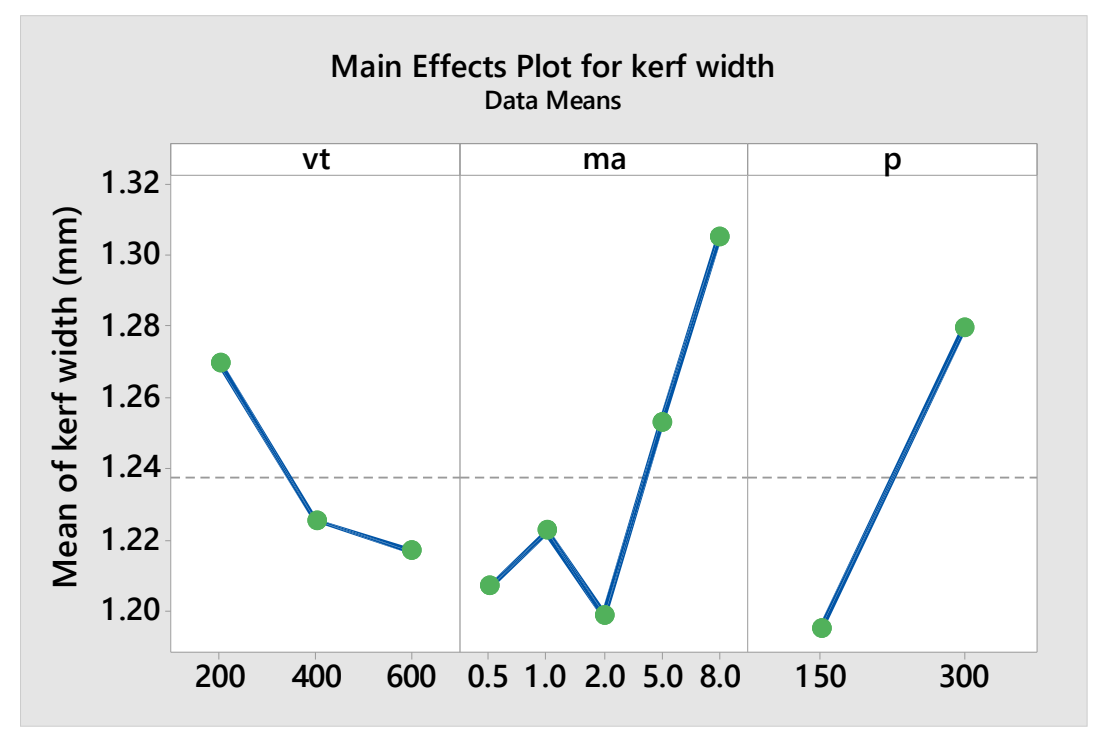

Figure 7. Variation of kerf width means values in respect to process parameters.

Kerf taper angle values are also important to be analyzed, as they indicate the straightness of a produced slot cross-section. In the case of kerf taper angle, the observed trends were influenced both by the trends of depth of penetration and the top and bottom kerf width values. The analysis of the experimental results indicated that increasing values of traverse speed led to higher kerf taper angle, and higher jet pressure led to lower kerf taper angle, as can be seen in Figure 8. The trend regarding the traverse speed can be explained by observing the mathematical formula relating kerf taper angle with depth of penetration and kerf width; as inverse tangent yields positive values for positive inputs and increases for positive values, despite the fact that both depth of penetration and kerf width are negatively correlated with traverse speed, the ratio of Equation (1) increases and subsequently leads to an increase in kerf taper angle. The increased jet pressure was found to increase both depth of penetration and kerf width; however, its impact was higher on depth of penetration, and thus the ratio of Equation (1) decreases, and the kerf taper angle decreases. Finally, for a similar reason as jet pressure, the abrasive mass flow rate affects negatively the kerf taper angle but up to a limit, as for values over $5 \mathrm{~g} / \mathrm{s}$, an increase is observed. This can be explained by the correlation between ma and depth of penetration, as it was shown that in most cases, at higher ma values, the depth of penetration remained almost constant, whereas the kerf width value increases. Thus, the ratio of Equation (1) also increases and the kerf taper angle becomes greater. The ANOVA results indicate that jet pressure is the dominant parameter in this case as its relevant significance is $73.34 \%$, 
followed by traverse speed $(20.28 \%)$ and abrasive mass flow rate $(6.38 \%)$. These results reveal that regulation of kerf taper angle at a constant stand-off distance can be effectively achieved by variation of jet pressure.

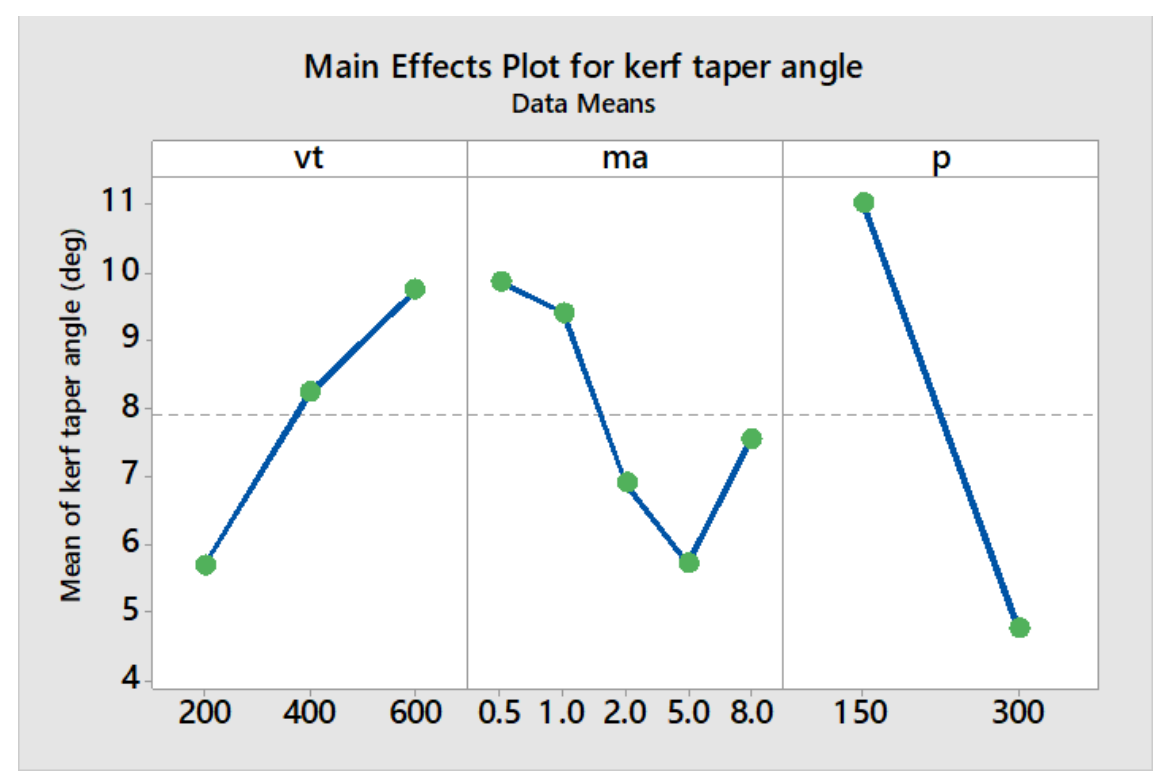

Figure 8. Variation of kerf taper angle means value in respect to process parameters.

\subsection{Sustainability Assessment Process}

\subsubsection{Sustainability Indicators}

With the fundamental results of the experiment having been discussed, the analysis of the various experimental cases regarding sustainability is now conducted. The evaluation is carried out according to the aforementioned procedure described in Section 2. Thus, the sustainability of processing of hard-to-cut alloy, such as titanium, using AWJ is evaluated based on multiple criteria that consist of single or multiple indicators/metrics. Afterwards, the various aspects and indicators included in the analysis, depicted in Figure 9, are discussed, and their values are presented. The goal is to include as many sustainability indicators as possible in order for the evaluation to be more comprehensive.

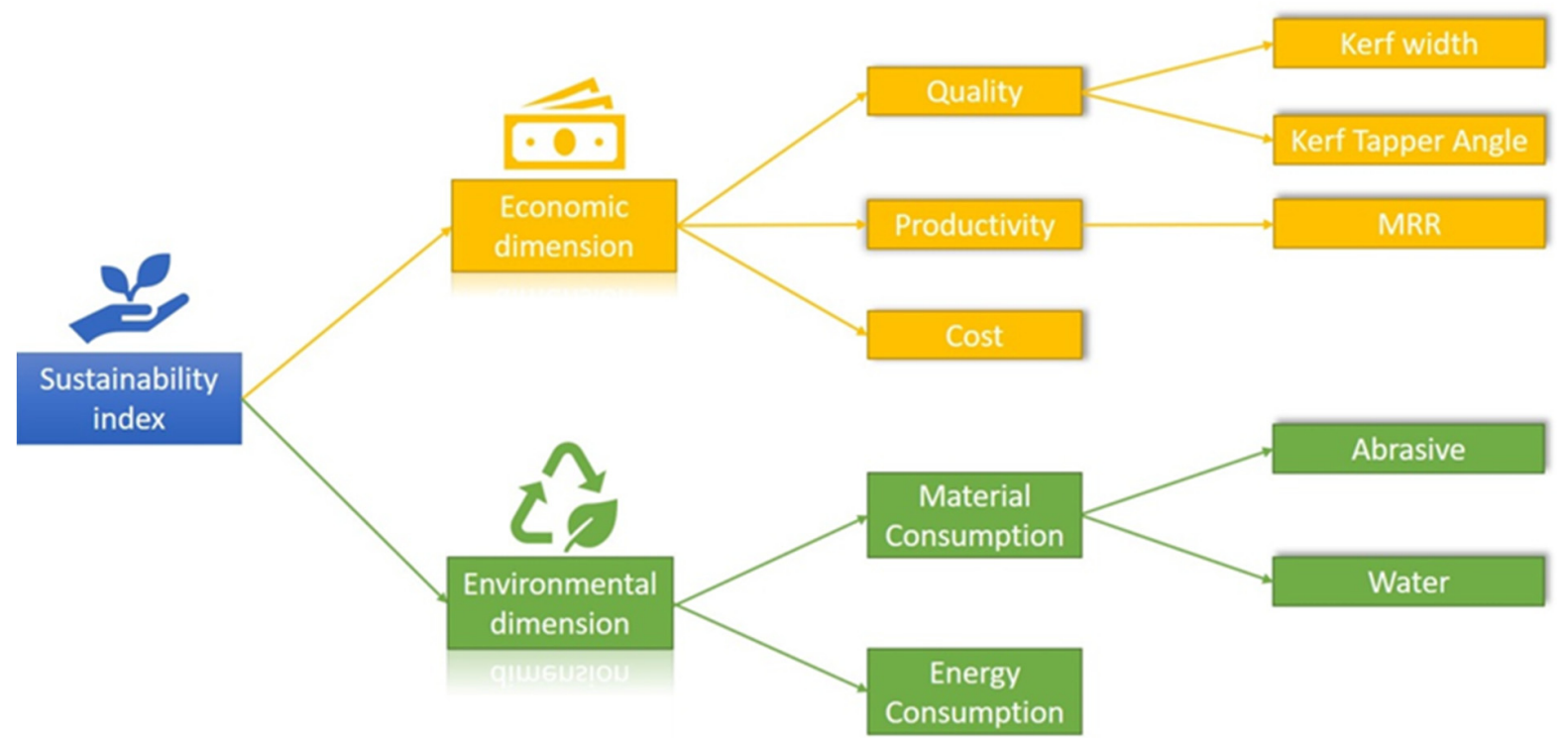

Figure 9. Sustainability dimensions and indicators considered in the present study. 
The quality of the obtained features, namely straight slots, is evaluated according to two indicators, namely kerf width and kerf taper angle. Ideally, it is desired that these two are minimized in order to obtain a slot closer to the ideal geometry. Material Removal Rate (MRR) is directly associated with the efficiency of the material process, as it is required that the task of creating the groove is performed as quickly as possible, taking into consideration the other restrictions as well. MRR is estimated by the measured topography of the grooves and the time required performing the cutting of the groove.

Consumption of both abrasive and water should not be excessive for different reasons. Although there is potential for recycling the abrasive and using it more than once, highly fragmented particles are not useful and thus can be considered as waste. On the other hand, water is a valuable resource and should not be wasted, and thus minimization of its consumption is also desirable. In this work, apart from the glass beads used for the experimental work, results from a previous experiment on the same workpiece conducted with garnet abrasive are also considered in order to conduct a comparison. The consumption of abrasive material is based on the abrasive mass flow rate, whereas the consumption of water is calculated based on water flow rate $\left(Q_{w}\right)$ as follows [51]:

$$
\mathrm{Q}_{\mathrm{w}}=\mathrm{c}_{\mathrm{d}} \frac{\pi \mathrm{d}_{0}^{2}}{4} \sqrt{\frac{2 \mathrm{p}}{\rho_{\mathrm{w}}}}
$$

where $c_{d}$ is the coefficient of discharge with values in the range $0.6-0.8$ (in this work, $c_{d}$ is assumed equal to 0.7 from [52]); $d_{0}$ is the orifice diameter, which is $0.3 \mathrm{~mm}$; and $\rho_{\mathrm{w}}$ is the density of the water, which is assumed equal to $1000 \mathrm{~kg} / \mathrm{m}^{3}$. Power consumption is also important to keep at relatively low levels in order to reduce electricity consumption. In this study, hydraulic power (Pw) is taken into account, which is calculated according to the values of water flow rate and jet pressure as their product $[51,52]$ :

$$
\mathrm{P}_{\mathrm{w}}=\mathrm{Q}_{\mathrm{w}} \times \mathrm{p}
$$

Cost of the material removal process is also an important aspect that should be taken into consideration, as it complies with one of the pillars of sustainability, namely the economic dimension. The total cost is calculated as the sum of five components, namely, the cost of abrasive particles, the cost of electric power, the cost of material, the cost of water, and the labor cost $[53,54]$ :

$$
\mathrm{C}_{\text {total }}=\mathrm{C}_{\mathrm{abr}}+\mathrm{C}_{\mathrm{el}}+\mathrm{C}_{\mathrm{mat}}+\mathrm{C}_{\mathrm{wat}}+\mathrm{C}_{\text {labor }}
$$

where Cabr $=\mathrm{ca} \times \mathrm{ma} \times \mathrm{tm}, \mathrm{C}_{\mathrm{el}}=\mathrm{c}_{\mathrm{e}} \times \mathrm{P} \times \mathrm{tm}, \mathrm{C}_{\text {mat }}=\mathrm{cm} \times \mathrm{MRR} \times \rho_{\mathrm{Ti}} \times \mathrm{t}_{\mathrm{m}}, \mathrm{C}_{\mathrm{wat}}=$ $c_{\mathrm{w}} \times \mathrm{Q}_{\mathrm{w}} \times \mathrm{t}_{\mathrm{m}}$, and $\mathrm{C}_{\text {labor }}=\mathrm{c}_{\mathrm{l}} \times \mathrm{t}_{\mathrm{m}}$. In the above equations, $\mathrm{c}_{\mathrm{a}}$ is the cost of abrasive per unit mass, which is equal to 3000 euro/tn in the case of garnet and 4000 euro/tn in the case of glass beads; $t_{m}$ is the machining time; $c_{e}$ is the cost of electricity, which is equal to 0.12 euro $/ \mathrm{kWh} ; \mathrm{c}_{\mathrm{m}}$ is the cost of workpiece materials, which is equal to 45 euro $/ \mathrm{kg} ; \rho_{\mathrm{Ti}}$ is the density of titanium, equal to $4400 \mathrm{~kg} / \mathrm{m}^{3} ; \mathrm{c}_{\mathrm{w}}$ is the cost of water, which is equal to 1.98 euro $/ \mathrm{m}^{3}$; and $\mathrm{c}_{1}$ is the labor cost, equal to 8 euro $/ \mathrm{h}$.

The categorization of the aforementioned indicators into hierarchical levels is depicted in the diagram of Figure 9. As can be seen, the indicators pertinent to the economic dimension of sustainability are those relevant to quality, productivity, and cost, and the indicators pertinent to the environmental dimension of sustainability are material and power consumption.

\subsubsection{Sustainability Assessment Method}

The method chosen for the sustainability assessment in the present work is Grey Relational Analysis (GRA), as this method is consistent with the steps described in Section 2. GRA is a method based on grey system theory, suitable for multi-objective optimization where the contributions from each individual objective are aggregated to calculate a total 
Grey Relational Grade. A grey relation contains incomplete information and can indicate the degree of correlation between two sequences, even in cases with few data. The first step in GRA method is the normalization of all responses in the range $0-1$ according to a specific objective. Normalization is essential for the initial sequence of data in order to avoid higher contribution of specific terms due to their higher values and enable proper comparison. When maximization is required for an objective, the "larger-is-better" expression is used as follows $[50,55]$ :

$$
\mathrm{z}_{\mathrm{ij}}=\frac{\mathrm{y}_{\mathrm{ij}}-\operatorname{miny}_{\mathrm{ij}}}{\operatorname{maxy}_{\mathrm{ij}}-\text { miny }_{\mathrm{ij}}}
$$

where $y_{i j}$ is the response for the $\mathrm{i}$-th experiment and the $\mathrm{j}$-th indicator and $\mathrm{z}_{\mathrm{ij}}$ the respective normalized response value. On the other hand, when minimization is desired, the "smalleris-better" expression is employed as follows [50,55]:

$$
\mathrm{z}_{\mathrm{ij}}=\frac{\operatorname{maxy}_{\mathrm{ij}}-\mathrm{y}_{\mathrm{ij}}}{\operatorname{maxy}_{\mathrm{ij}}-\text { miny }_{\mathrm{ij}}}
$$

In cases where a specific target value is desired, the "nominal-the-best" expression is used as follows:

$$
z_{i j}=1-\frac{\left|y_{i j}-y_{o j}\right|}{\operatorname{maxy}_{i j}-y_{o j}}
$$

where $y_{o j}$ is the desired target value for the $\mathrm{j}$-th indicator. The next step of GRA method consists of the calculation of Grey Relational Coefficients (GRC) based on the normalized values. Using the GRC, the ideal value of the response is related to the normalized experimental results. The GRC are calculated as follows [50,55]:

$$
\gamma\left(\mathrm{Z}_{0}, \mathrm{Z}_{\mathrm{ij}}\right)=\frac{\Delta \min +\xi \Delta \max }{\Delta_{0 \mathrm{j}}(\mathrm{k})+\xi \Delta \max }
$$

where $Z_{0}(k)$ is called the reference sequence with $\mathrm{k}=1 \mathrm{~m}, \ldots, \mathrm{m}$ and $\mathrm{m}$ equal to the number of indicators; $\Delta_{0 j}(k)$ is the deviation sequence of the respective $Z_{\mathrm{o}}(\mathrm{k})$; and $Z_{\mathrm{ij}}(\mathrm{k})$ is the comparability sequence, so that $\Delta_{0 \mathrm{j}}(\mathrm{k})=\left|\mathrm{Z}_{\mathrm{o}}(\mathrm{k})-\mathrm{Z}_{\mathrm{ij}}(\mathrm{k})\right|$ and $\Delta \max$ and $\Delta \mathrm{min}$ are the highest and lowest values of the $\Delta_{0 j}(\mathrm{k})$ sequence. In this study, the value of distinguishing coefficient $\xi$, which is considered to vary in the range $0-1$, is assumed to equal to 0.5 .

Finally, the Grey Relational Grade (GRG) can be calculated by the values of the GRC and the weight factors $\omega \mathrm{k}$ as can be seen in Equation (9). This value can reveal the degree of correlation between two sequences, with a higher GRG value showing a higher degree of correlation between a sequence and the ideal one.

$$
\operatorname{GRG}\left(Z_{0}, Z_{\mathrm{ij}}\right)=\sum_{\mathrm{k}=1}^{\mathrm{n}} \omega_{\mathrm{k}} \gamma\left(\mathrm{Z}_{0}, \mathrm{Z}_{\mathrm{ij}}\right)
$$

A simple way to calculate the GRG is to assign equal weights to the GRC in order to give them equal importance. However, in other cases, special strategies are employed to determine more specific weights.

\subsection{Sustainability Assessment Results}

In order to conduct the sustainability assessment, the results of Table 5 regarding the sustainability indicators are firstly normalized. For kerf width, kerf taper angle, cost, abrasive, and water and power consumption, the "smaller-is-better" function was employed, whereas for the MRR, the "larger-is-better" function was employed. Then, the Grey Relational Coefficients are calculated for each indicator and are aggregated, firstly according to their subcategory with equal coefficients, e.g., in the case of quality, and finally, the Grey Relational Grade is calculated in every case. In Figure 10, the total sustainability index, corresponding to the Grey Relational Grade value in each case, is depicted. 
Table 5. Sustainability indicators' values.

\begin{tabular}{|c|c|c|c|c|c|c|c|}
\hline No. & $\mathrm{W}(\mathrm{mm})$ & a (deg) & $\begin{array}{c}\text { MRR } \\
\left(\mathrm{mm}^{3} / \mathrm{s}\right)\end{array}$ & $P_{w}(W)$ & $c_{a b r}(g)$ & $\mathrm{c}_{\mathrm{wat}}(\mathrm{L})$ & Cost $(€)$ \\
\hline 1 & 1.192 & 10.518 & 2.458 & 3658.683 & 9 & 0.439 & 0.088 \\
\hline 2 & 1.146 & 15.027 & 3.429 & 3658.683 & 4.5 & 0.220 & 0.046 \\
\hline 3 & 1.102 & 14.089 & 3.799 & 3658.683 & 3 & 0.146 & 0.031 \\
\hline 4 & 1.170 & 8.358 & 2.810 & 3658.683 & 18 & 0.439 & 0.125 \\
\hline 5 & 1.181 & 10.282 & 4.116 & 3658.683 & 9 & 0.220 & 0.065 \\
\hline 6 & 1.125 & 20.685 & 4.191 & 3658.683 & 6 & 0.146 & 0.043 \\
\hline 7 & 1.158 & 7.458 & 2.907 & 3658.683 & 36 & 0.439 & 0.197 \\
\hline 8 & 1.152 & 10.098 & 4.205 & 3658.683 & 18 & 0.220 & 0.101 \\
\hline 9 & 1.135 & 9.738 & 5.616 & 3658.683 & 12 & 0.146 & 0.069 \\
\hline 10 & 1.236 & 7.997 & 3.647 & 3658.683 & 90 & 0.439 & 0.416 \\
\hline 11 & 1.175 & 9.598 & 4.661 & 3658.683 & 45 & 0.220 & 0.210 \\
\hline 12 & 1.295 & 15.951 & 6.036 & 3658.683 & 30 & 0.146 & 0.142 \\
\hline 13 & 1.345 & 10.142 & 4.249 & 3658.683 & 144 & 0.439 & 0.634 \\
\hline 14 & 1.259 & 10.663 & 5.146 & 3658.683 & 72 & 0.220 & 0.319 \\
\hline 15 & 1.254 & 14.208 & 6.345 & 3658.683 & 48 & 0.146 & 0.214 \\
\hline 16 & 1.286 & 4.8603 & 9.246 & $10,348.320$ & 9 & 0.621 & 0.116 \\
\hline 17 & 1.263 & 6.889 & 9.019 & $10,348.320$ & 4.5 & 0.310 & 0.058 \\
\hline 18 & 1.253 & 7.816 & 10.422 & $10,348.320$ & 3 & 0.207 & 0.040 \\
\hline 19 & 1.334 & 3.083 & 13.427 & $10,348.320$ & 18 & 0.621 & 0.167 \\
\hline 20 & 1.270 & 6.320 & 12.759 & $10,348.320$ & 9 & 0.310 & 0.082 \\
\hline 21 & 1.256 & 7.800 & 12.194 & $10,348.320$ & 6 & 0.207 & 0.054 \\
\hline 22 & 1.327 & 2.214 & 16.010 & $10,348.320$ & 36 & 0.621 & 0.248 \\
\hline 23 & 1.200 & 4.907 & 13.859 & $10,348.320$ & 18 & 0.310 & 0.120 \\
\hline 24 & 1.222 & 7.033 & 13.744 & $10,348.320$ & 12 & 0.207 & 0.080 \\
\hline 25 & 1.272 & 0.887 & 27.202 & $10,348.320$ & 90 & 0.621 & 0.504 \\
\hline 26 & 1.275 & 4.319 & 22.114 & $10,348.320$ & 45 & 0.310 & 0.243 \\
\hline 27 & 1.266 & 4.947 & 19.735 & $10,348.320$ & 30 & 0.207 & 0.159 \\
\hline 28 & 1.375 & 1.526 & 31.564 & $10,348.320$ & 144 & 0.621 & 0.736 \\
\hline 29 & 1.335 & 4.247 & 27.185 & $10,348.320$ & 72 & 0.310 & 0.360 \\
\hline 30 & 1.261 & 4.525 & 21.873 & $10,348.320$ & 48 & 0.207 & 0.234 \\
\hline
\end{tabular}

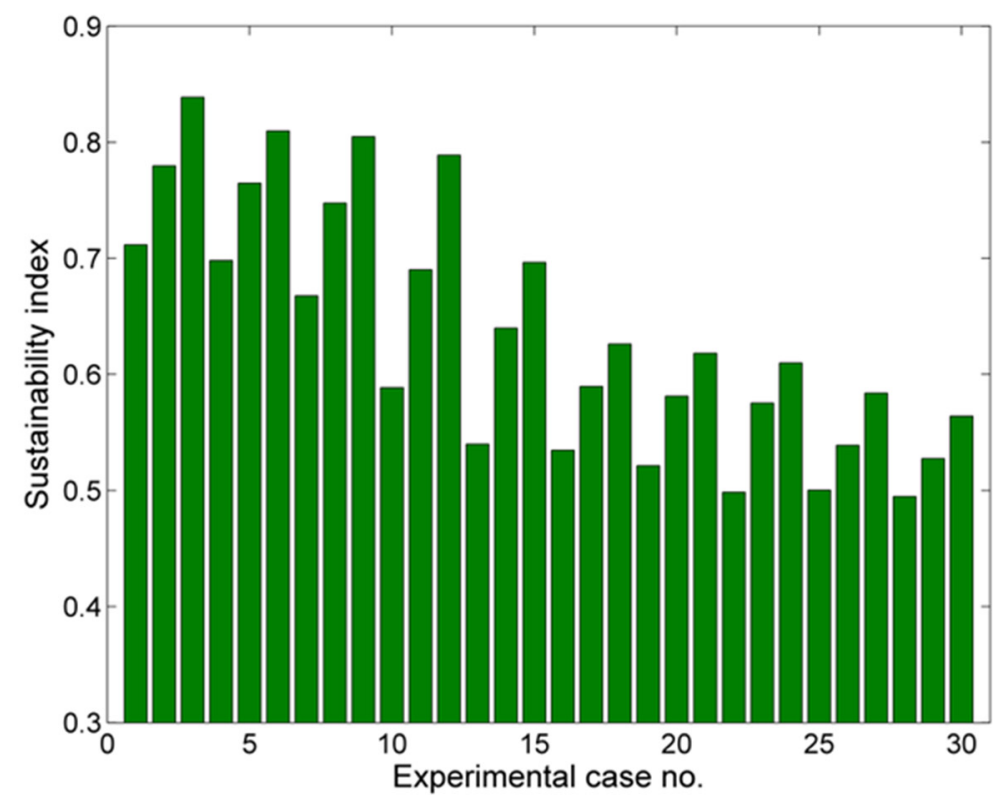

Figure 10. Sustainability index values in each experimental case.

As can be observed from Figure 10, the values of the sustainability index vary considerably with the different process conditions. In general, highest values are observed in cases where the machining time is lower, as well as cases with low consumption of 
abrasive and water and low cost. The highest sustainability index is obtained for the third experimental case, with traverse speed of $600 \mathrm{~mm} / \mathrm{min}$, abrasive mass flow rate of 0.5 $\mathrm{g} / \mathrm{s}$, and jet pressure of $150 \mathrm{MPa}$, which enables the achievement of both relatively high economic and environmental scores. Finally, it can be concluded that the GRA method played a decisive role in the determination of optimum conditions due to its simplicity and high effectiveness. With this method, further studies can be conducted, including other indicators as well with minimal changes.

\section{Conclusions}

In this work, experimental tests regarding AWJM of Ti-6Al-4V were carried out in order to conduct a comprehensive evaluation of the sustainability of AWJM of hard-to-cut materials. In the experimental tests, glass beads were selected as the abrasive materials, and various important quantities such as depth of penetration, kerf width, and kerf taper angle were measured. After the results were analyzed, various conclusions were drawn.

First, AWJM of titanium alloys with glass beads was shown to be relatively effective, although this abrasive material is not as hard as common abrasives. The anticipated trends were observed regarding depth of penetration, and jet pressure was determined to be the most important parameter, followed by traverse speed and abrasive mass flow rate. Kerf width was also affected mainly by jet pressure for constant stand-off distance values, as well as kerf taper angle. The variation of abrasive mass flow rate in all cases showed different behaviors for different ranges of values, as depth of penetration remained almost constant for larger values of abrasive mass flow rate, kerf width increased clearly for values of ma only above $2 \mathrm{~g} / \mathrm{s}$, and kerf taper angle was reduced for values of ma up to $5 \mathrm{~g} / \mathrm{s}$.

Using GRA method, sustainability assessment was able to be carried out, taking into consideration various indicators both from the economic and environmental dimensions of sustainability. For the economic dimension, workpiece quality, productivity and cost indicators were considered, whereas for the environmental dimension, material and power consumption were used. The results revealed that the case with a traverse speed of $600 \mathrm{~mm} / \mathrm{min}$, abrasive mass flow rate of $0.5 \mathrm{~g} / \mathrm{s}$, and jet pressure $150 \mathrm{MPa}$ provided the highest sustainability index value, leading to the best possible performance in both the economic and environmental dimensions. Moreover, it was observed that the GRA method was simple to use but also very effective towards the handling of multiple objectives, leading to the creation of a flexible framework that can be altered by adding or removing various indicators if it is required.

Author Contributions: Conceptualization, P.K.-O. and N.E.K.; methodology, P.K.-O., R.K. and N.E.K.; software, P.K.-O. and N.E.K.; validation, P.K.-O., N.E.K. and R.K.; formal analysis, N.E.K.; investigation, P.K.-O.; resources, P.K.-O. and A.P.M.; data curation, N.E.K.; writing-original draft preparation, P.K.-O. and N.E.K.; writing-review and editing, R.K. and A.P.M.; visualization, P.K.-O. and N.E.K.; supervision, R.K. and A.P.M.; project administration, P.K.-O. and A.P.M.; funding acquisition, A.P.M. All authors have read and agreed to the published version of the manuscript.

Funding: This research received no external funding.

Institutional Review Board Statement: Not applicable.

Informed Consent Statement: Not applicable.

Data Availability Statement: The data presented in this study are available on request from the corresponding author.

Conflicts of Interest: The authors declare no conflict of interest.

\section{References}

1. Saad, M.H.; Nazzal, M.A.; Darras, B.M. A general framework for sustainability assessment of manufacturing processes. Ecol. Indic. 2019, 97, 211-224. [CrossRef]

2. Manufacturing Value Added Data. Available online: https://data.worldbank.org/indicator/NV.IND.MANF.CD (accessed on 25 June 2021). 
3. Zackrisson, M.; Enroth, M.; Widing, A. Environmental Management Systems—Paper Tiger or Powerful Tool. In 2000 EcoManagement and Auditing Conference; IVF Research Publication: Molndal, Sweden, 2000.

4. Krolczyk, G.M.; Maruda, R.W.; Krolczyk, J.B.; Wojciechowski, S.; Mia, M.; Nieslony, P.; Budzik, G. Ecological trends in machining as a key factor in sustainable production-A review. J. Clean. Prod. 2019, 218, 601-615. [CrossRef]

5. Tamilarasan, A.; Arumugam, S.; Rajamani, D.; Changareddy, P.; Balasubramanian, E.; Pranay, P. Multi-response Optimization of AWJ Process Parameters in Cut Quality Characteristics of Hastelloy C-276. In Advances in Materials and Manufacturing Engineering; Rajmohan, T., Palanikumar, K., Davim, J.P., Eds.; Springer: Singapore, 2021; Volume 7, pp. 381-388. [CrossRef]

6. Chen, M.; Zhang, S.; Zeng, J.; Chen, B. Correcting shape error located in cut-in/cut-out region in abrasive water jet cutting process. Int. J. Adv. Manuf. Technol. 2019, 102, 1165-1178. [CrossRef]

7. Karmiris-Obratański, P.; Karkalos, N.E.; Kudelski, R.; Papazoglou, E.L.; Markopoulos, A.P. On the Effect of Multiple Passes on Kerf Characteristics and Efficiency of Abrasive Waterjet Cutting. Metals 2021, 11, 74. [CrossRef]

8. Yuvaraj, N.; Murugesan, P.K.; Mohan, M.; Khan, S.A.L.A. Abrasive Water Jet Machining process: A state of art of review. J. Manuf. Process. 2020, 49, 271-322.

9. Kale, A.; Singh, S.K.; Sateesh, N.; Subbiah, R. A review on abrasive water jet machining process and its process parameters. Mater. Today Proc. 2020, 26, 1032-1036. [CrossRef]

10. Rabani, A.; Madariaga, J.; Bouvier, C.; Axinte, D. An approach for using iterative learning for controlling the jet penetration depth in abrasive waterjet milling. J. Manuf. Process. 2016, 22, 99-107. [CrossRef]

11. Perec, A. Experimental research into alternative abrasive material for the abrasive water-jet cutting of titanium. Int. J. Adv. Manuf. Technol. 2018, 97, 1529-1540. [CrossRef]

12. Yuan, Y.; Chen, J.; Gao, H.; Wang, X. An investigation into the abrasive waterjet milling circular pocket on titanium alloy. Int. J. Adv. Manuf. Technol. 2020, 107, 4503-4515. [CrossRef]

13. Alberdi, A.; Rivero, A.; López de Lacalle, L.N.; Etxeberria, I.; Suárez, A. Effect of process parameter on the kerf geometry in abrasive water jet milling. Int. J. Adv. Manuf. Technol. 2010, 51, 467-480. [CrossRef]

14. Uhlmann, E.; Männel, C.; Braun, T. Efficient abrasive water jet milling for near-net-shape fabrication of difficult-to-cut materials. Int. J. Adv. Manuf. Technol. 2020, 111, 685-693. [CrossRef]

15. Chithirai Pon Selvan, M.; Midhunchakkaravarthy, D.; Senanayake, R.; Ramaswamy Pillai, S.; Reddy Madara, S. A mathematical modelling of Abrasive Waterjet Machining on Ti-6Al-4V using Artificial Neural Network. Mater. Today Proc. 2020, $28,538-544$. [CrossRef]

16. Chen, F.L.; Siores, E.; Patel, K.; Momber, A.W. Minimising particle contamination at abrasive waterjet machined surfaces by a nozzle oscillation technique. Int. J. Mach. Tools Manuf. 2002, 42, 1385-1390. [CrossRef]

17. Rivero, A.; Alberdi, A.; Artaza, T.; Mendia, L.; Lamikiz, A. Surface properties and fatigue failure analysis of alloy 718 surfaces milled by abrasive and plain waterjet. Int. J. Adv. Manuf. Technol. 2018, 94, 2929-2938. [CrossRef]

18. Fowler, G.; Shipway, P.H.; Pashby, I.R. A technical note on grit embedment following abrasive water-jet milling of a titanium alloy. J. Mater. Process. Technol. 2005, 159, 356-368. [CrossRef]

19. Boud, F.; Carpenter, C.; Folkes, J.; Shipway, P.H. Abrasive waterjet cutting of a titanium alloy: The influence of abrasive morphology and mechanical properties on workpiece grit embedment and cut quality. J. Mater. Process. Technol. 2010, 210, 2197-2205. [CrossRef]

20. Hashish, M. Characteristics of surfaces machined with abrasive water jets. J. Eng. Mater. Tech. 1991, 113, 354-362. [CrossRef]

21. Bergs, T.; Schüler, M.; Dadgar, M.; Herrig, T.; Klink, A. Investigation of Waterjet Phases on Material Removal Characteristics. Procedia CIRP 2020, 95, 12-17. [CrossRef]

22. Stachowiak, G.B.; Stachowiak, G.W. The effects of particle characteristics on three body abrasive wear. Wear 2001, 249, 201-207. [CrossRef]

23. Fowler, G.; Pashby, I.R.; Shipway, P.H. The effect of particle hardness and shape when abrasive water jet milling titanium alloy Ti6Al4V. Wear 2009, 266, 613-620. [CrossRef]

24. Fowler, G.; Shipway, P.H.; Pashby, I.R. Abrasive water-jet controlled depth milling of Ti6Al4V alloy-An investigation of the role of jet-Workpiece traverse speed and abrasive grit size on the characteristics of the milled material. J. Mater. Process. Technol. 2005, 161, 407-414. [CrossRef]

25. Yu, Y.; Sun, T.; Yuan, Y.; Gao, H.; Wang, X. Experimental investigation into the effect of abrasive process parameters on the cutting performance for abrasive waterjet technology: A case study. Int. J. Adv. Manuf. Technol. 2020, 107, 2757-2765. [CrossRef]

26. Boud, F.; Murray, J.W.; Loo, L.F.; Clare, A.T.; Kinnell, P.K. Soluble abrasives for Waterjet Machining. Mater. Manuf. Process. 2014, 29, 1346-1352. [CrossRef]

27. Kantha Babu, M.; Krishnaiah Chetty, O.V. Studies on recharging of abrasives in abrasive water jet machining. Int. J. Adv. Manuf. Technol. 2002, 19, 697-703. [CrossRef]

28. Sabarinatha, P.; Annamalai, V.E.; Rajkumar, K. Sustainable application of grinding wheel waste as abrasive for abrasive water jet machining process. J. Clean. Prod. 2020, 261, 121225. [CrossRef]

29. Kandasamy, J.; Vimal, K.E.K.; Sethuram, L. Quantification of environmental impacts of abrasive water jet cutting process through sustainability analysis. Int. J. Environ. Sustain. Dev. 2019, 18, 101-119. [CrossRef]

30. Natarajan, Y.; Murugasen, P.K.; Sundarajan, L.R.; Arunachalam, R. Experimental investigation on cryogenic assisted abrasive water jet machining of aluminum alloy. Int. J. Precis. Eng. Manuf. Green Technol. 2019, 6, 415-432. [CrossRef] 
31. Pradhan, S.; Das, S.R.; Dhupal, D. Performance evaluation of recently developed new process HAJM during machining hardstone quartz using hot silicon carbide abrasives: An experimental investigation and sustainability assessment. Silicon 2020, 1-25. [CrossRef]

32. Gupta, K.; Avvari, M.; Mashamba, A.; Mallaiah, M. Ice Jet Machining: A Sustainable Variant of Abrasive Water Jet Machining. In Sustainable Machining, 1st ed.; Davim, J.P., Ed.; Springer International Publishing: Cham, Switzerland, 2017 ; pp. 67-78.

33. Jayal, A.D.; Badurdeen, F.; Dillon, O.W., Jr.; Jawahir, I.S. Sustainable manufacturing: Modeling and optimization challenges at the product, process and system levels. CIRP J. Manuf. Sci. Technol. 2010, 2, 144-152. [CrossRef]

34. Khan, A.M.; Anwar, S.; Gupta, M.K.; Alfaify, A.; Hasnain, S.; Jamil, M.; Mia, M.; Pimenov, D.Y. Energy-based novel quantifiable sustainability value assessment method for machining processes. Energies 2020, 13, 6144. [CrossRef]

35. Hegab, H.A.; Darras, B.; Kishawy, H.A. Towards sustainability assessment of machining processes. J. Clean. Prod. 2018, 170, 694-703. [CrossRef]

36. Badurdeen, F.; Shuaib, M.A.; Lu, T.; Jawahir, I.S. Sustainable Value Creation in Manufacturing at Product and Process Levels: A Metrics-based Evaluation. In Handbook of Manufacturing Engineering and Technology, 1st ed.; Nee, A., Ed.; Springer: London, UK, 2014; pp. 1-28.

37. Peralta, M.E.; Bárcena, M.M.; González, F.A. On the sustainability of machining processes. Proposal for a unified framework through the triple bottom-line from an understanding review. J. Clean. Prod. 2017, 142, 3890-3904. [CrossRef]

38. Jamil, M.; Zhao, W.; He, N.; Gupta, M.K.; Sarikaya, M.; Khan, A.M.; Sanjay, M.R.; Siengchin, S.; Pimenov, D.Y. Sustainable milling of Ti-6Al-4V: A trade-off between energy efficiency, carbon emissions and machining characteristics under MQL and cryogenic environment. J. Clean. Prod. 2021, 281, 125374. [CrossRef]

39. Bork, C.A.S.; de Sousa, J.F.; de Oliveira Gomes, J.; Canhete, V.V.P.; de Barba, D.J., Jr. Methodological tools for assessing the sustainability index (SI) of industrial production processes. Int. J. Adv. Manuf. Technol. 2016, 87, 1313-1325. [CrossRef]

40. Jawahir, I.S.; Wanigarthne, P.C.; Wang, X. Product Design and Manufacturing Processes for Sustainability. In Mechanical Engineers' Handbook; John Wiley and Sons, Inc.: Hoboken, NJ, USA, 2015; Volume 2, p. 177.

41. Gholami, H.; Mat Saman, M.Z.; Sharif, S.; Md Khudzari, J.; Zakuan, N.; Streimikiene, D.; Streimikis, J. A general framework for sustainability assessment of sheet metalworking processes. Sustainability 2020, 12, 4957. [CrossRef]

42. Singh, R.K.; Murty, H.R.; Gupta, S.K.; Dikshit, A.K. An overview of sustainability assessment methodologies. Ecol. Indic. 2009, 9, 189-212. [CrossRef]

43. Najiha, M.S.; Rahman, M.M.; Kadirgama, K. Performance of water-based $\mathrm{TiO}_{2}$ nanofluid during the minimum quantity lubrication machining of aluminium alloy, AA6061-T6. J. Clean. Prod. 2016, 135, 1623-1636. [CrossRef]

44. Kim, D.B.; Leong, S.; Chen, C.S. An Overview of Sustainability Indicators and Metrics for Discrete Part Manufacturing. In Proceedings of the ASME 2012 International Design Engineering Technical Conference \& Computers and Information in Engineering Conference IDETC/CIE 2012, Chicago, IL, USA, 12-15 August 2012.

45. Feng, S.C.; Joung, C.; Li, G. Development Overview of Sustainable Manufacturing Metrics. In Proceedings of the 17th CIRP International Conference of Life Cycle Engineering, Hefei, China, 19-21 May 2010.

46. Wang, Q.; Liu, F.; Li, C. An integrated method for assessing the energy efficiency of machining workshop. J. Clean. Prod. 2013, 52, 122-133. [CrossRef]

47. Bhat, P.; Agrawal, C.; Khanna, N. Development of a sustainability assessment algorithm and its validation using case studies on cryogenic machining. J. Manuf. Mater. Process. 2020, 4, 42. [CrossRef]

48. Sihag, N.; Sangwan, K.S. Development of a sustainability assessment index for machine tools. Procedia CIRP 2019, 80, 156-161. [CrossRef]

49. Kaldas, O.; Shihata, L.A.; Kiefer, J. An index-based sustainability assessment framework for manufacturing organizations. Procedia CIRP 2020, 97, 235-240. [CrossRef]

50. Younas, M.; Jaffery, S.H.I.; Khan, M.; Khan, M.A.; Ahmad, R.; Mubashar, A.; Ali, L. Multi-objective optimization for sustainable turning Ti6Al4V alloy using grey relational analysis (GRA) based on analytic hierarchy process (AHP). Int. J. Adv. Manuf. Technol. 2019, 105, 1175-1188. [CrossRef]

51. Radovanović, M.R. Performances of abrasive water jet cutting with hyper pressure. Int. J. Modeling Optim. 2017, 7, 275-279. [CrossRef]

52. Schwartzentruber, J.; Spelt, J.K.; Papini, M. Modeling of delamination due to hydraulic shock when piercing anisotropic carbon-fiber laminates using an abrasive waterjet. Int. J. Mach. Tools Manuf. 2018, 132, 81-95. [CrossRef]

53. Pi, V.N.; Hoogstrate, A.M. Cost calculation for recycled abrasives and for abrasive selecting in abrasive waterjet machining. Int. J. Precis. Mach. 2007, 1, 40-54. [CrossRef]

54. Radovanović, M. Cost optimization of abrasive water jet cutting using GA. Tribol. J. BULTRIB 2013, 3, 70-75.

55. Yan, J.; Li, L. Multi-objective optimization of milling parameters—the trade-offs between energy, production rate and cutting quality. J. Clean. Prod. 2013, 52, 462-471. [CrossRef] 